Article

\title{
Differences in the quality of life of chronic kidney disease patients undergoing hemodialysis and continuous ambulatory peritoneal dialysis
}

\author{
Ika Setyo Rini, ${ }^{1}$ Titik Rahmayani, ${ }^{2}$ Efris Kartika Sari, ${ }^{1}$ Retno Lestari ${ }^{1}$ \\ ${ }^{1}$ School of Nursing, Faculty of Medicine, Universitas Brawijaya, Malang, Indonesia; ${ }^{2}$ Dr. Saiful Anwar General \\ Hospital Malang, Indonesia
}

\begin{abstract}
Background: Chronic kidney disease (CKD) is defined as a progressive disease that causes renal failure and requires extended and long-term therapies. CKD patients need to choose one of these therapies to improve their quality of life. This study aims to investigate differences in the quality of life of chronic kidney disease patients undergoing hemodialysis and continuous ambulatory peritoneal dialysis (CAPD).

Design and Methods: The study design used is similar to the cross-sectional design. Therefore, in this study observations were carried out, an EQ_5D life quality questionnaire sheet was administered to respondents, and a purposive sampling method was used. The total number of respondents was 250 and consisted of 125 hemodialysis and CAPD patients each.

Results: The results obtained using the Mann Whitney method was a $p$-value $(0.515)>\alpha(0.05)$. These results also included five components, namely the ability to move/walk to an acceptable degree, adequate self-care, performance of usual activities, minimal amount of pain/discomfort during hemodialysis and CAPD, and acceptable levels of anxiety/sadness.

Conclusions: This research concludes that there is no difference in the quality of life between CKD patients undergoing hemodialysis and CAPD.
\end{abstract}

\section{Introduction}

Chronic kidney disease (CKD) is becoming a global problem with increasing rates of incidences and high medical costs. However, previous studies regarding the risk factors of CKD are limited for low-income and middle-income countries. ${ }^{1} \mathrm{CKD}$ is also one of COVID-19 co-morbidities (they usually appear together). In older adults, several comorbidities are commonly found in patients diagnosed with COVID-19, examples are CKD, dementia, depression, and atrial fibrillation. ${ }^{2}$ All CKD patients require a form of renal replacement therapy such as hemodialysis, CAPD, and kidney transplant.
The prevalence of CKD stage 1 to 5 was $8.66 \%$ in African countries like Senegal, and Congo, $9.07 \%$ in Malaysia and $18.38 \%$ in Europe. Indonesia has no definite data on the prevalence of CKD, but Riset Kesehatan Dasar/Basic Health Research (Riskesdas) reported that $0.2 \%$ of Indonesia's population suffered from this ailment in 2013. CKD is a progressive disease, therefore its treatment is costly, as it requires hemodialysis or other treatments to prevent death in the late stages. In 2017, among 30,831 new hemodialysis patients in Indonesia, more than $48.3 \%$ were diagnosed with hypertension or diabetes and $4 \%$ of them were having unknown etiology. ${ }^{3}$ Renal replacement therapy is very beneficial to $\mathrm{CKD}$ patients because the kidneys are vital organs in the body which maintains homeostasis. However, dialysis therapy comes with its risks and side effects, as various problems and complications can occur in patients undergo the process. CKD sufferers must choose to go through therapy in order to survive the disease and prolong their lives. Dialysis is closely link to the quality of life the patient experiences because of the many complex problems associated with their illness. These problems can be physical, psychological, social, economic and spiritual. Quality of life is the sum of individuals' perception of their abilities, limitations, symptoms and psychosocial characteristics. It can be defined based on culture and value systems and it plays a part in how people carry out their roles and functions. People suffering from CKD experience a decrease in their quality of life which affects their physical, mental and social well-being. However, social support may play an important role for these individuals. ${ }^{4}$

In comparison with healthy individuals, hemodialysis (HD) patients have diminished their quality-of-life scores and negatively impact on the mental health. Many HD patients feel hopeless, worried with regards to additional burden of diseases, and loss of their independence. ${ }^{5}$ Patients with chronic kidney disease tend to need employment to pay for their renal replacement therapy. This constitutes an important advantage for their employers as the patients will never miss work due to the health issues and the need for financial safety. ${ }^{6}$ Therefore, this study aims to investigate differences in the quality of life of patients with CKD undergoing hemodialysis and continuous ambulatory peritoneal dialysis (CAPD).

Significance for public health

Information about the quality of life a person experiences during sickness should be provided to patients and families that suffer from CKD. These patients would undergo hemodialysis and CAPD, therefore they should be informed about how the quality of their, with respect to how they would carry out normal activities and pain management. This paper describes the quality of life of chronic kidney disease patients undergoing hemodialysis and continuous ambulatory peritoneal dialysis. 


\section{Design and Methods}

The research design used was similar to the cross-sectional approach carried out through observational study and the provision of the EQ_5D quality of life questionnaire sheet. Furthermore, the subjects used in this study were CKD patients undergoing hemodialysis and CAPD the hospital and were selected using a purposive sampling method. The total number of respondents were 250 people. This research was conducted from September to November 2019. The independent variables in this study are hemodialysis and CAPD, while the dependent variable is the level of quality of life. The instrument used for this study was the EuroQoL-5 Dimension questionnaire sheet (EQ-5D which had been tested for validity and reliability by previous researchers. Consequently, there were five questions in the questionnaire which covered several dimensions, such as the respondent's ability to walk/move, self-care, activities involved in, level of pain/discomfort and level of anxiety/depression. Each dimension of the questionnaire had three closed answer options. ${ }^{7}$ The data obtained was analyzed using the Mann Whitney statistical test to determine dif- ferences in quality of life of CKD patients undergoing hemodialysis and CAPD. In the Methods section, authors should state the authority which provided ethical approval for the study, along with a statement showing the informed consent of participants. The study or clinical trial registration number should also be provided, if applicable.

\section{Results and Discussions}

Table 1 shows a total of 250 respondents consisting of 125 hemodialysis patients and 125 patients undergoing CAPD. The majority of respondents were male, aged between 46-55 years, educated, private work, had been on hemodialysis for 3-6 years or CAPD for 1-3 years, and had no comorbidities. Table 2 describes that in general the overall quality of life of patients undergoing hemodialysis is at a good degree, with 103 people having an average score of $82.4 \%$. Five components of quality of life were studied with the following results: 89 people $(71.2 \%)$ had the ability to walk/move to a good degree, 116 people $(92.8 \%)$ had good self-

Table 1. General characteristics of respondents undergoing hemodialysis and continuous ambulatory peritoneal dialysis.

\begin{tabular}{|c|c|c|c|c|c|}
\hline \multirow[t]{2}{*}{ Indicator } & \multirow[t]{2}{*}{ Category } & \multicolumn{2}{|c|}{ Hemodialysis } & \multicolumn{2}{|c|}{ CAPD } \\
\hline & & n & $\%$ & n & $\%$ \\
\hline \multirow[t]{2}{*}{ Gender } & Male & 66 & 52.8 & 71 & 56.8 \\
\hline & Female & 59 & 47.2 & 54 & 43.2 \\
\hline \multirow[t]{5}{*}{ Age } & $17-25$ years old & 2 & 1.6 & 7 & 5.6 \\
\hline & 26-35 years old & 12 & 9.6 & 17 & 13.6 \\
\hline & $36-45$ years old & 33 & 26.4 & 31 & 24.8 \\
\hline & $46-55$ years old & 45 & 36 & 37 & 29.6 \\
\hline & $56-65$ years old & 33 & 26.4 & 33 & 26.4 \\
\hline \multirow[t]{4}{*}{ Education } & Primary School & 41 & 32.8 & 15 & 12 \\
\hline & Junior High School & 19 & 15.2 & 19 & 15.2 \\
\hline & Senior High School & 50 & 40 & 46 & 36.8 \\
\hline & College & 15 & 12 & 45 & 36 \\
\hline \multirow[t]{6}{*}{ Profession } & Government employees & 13 & 10.4 & 13 & 10.4 \\
\hline & Pensionary & 1 & 0.8 & 12 & 9.6 \\
\hline & Farmer & 4 & 3.2 & 2 & 1.6 \\
\hline & Private sector worker & 54 & 43.2 & 61 & 48.8 \\
\hline & Housewife & 26 & 20.8 & 23 & 18.4 \\
\hline & Unemployment & 27 & 21.6 & 14 & 11.2 \\
\hline \multirow[t]{6}{*}{ Duration of therapy } & 6- 12 months & 23 & 18.4 & 29 & 23.2 \\
\hline & 1-3 years & 30 & 24.0 & 57 & 45.6 \\
\hline & $3-6$ years & 44 & 35.2 & 22 & 17.6 \\
\hline & $6-9$ years & 12 & 9.6 & 15 & 12.0 \\
\hline & $9-12$ years & 10 & 8.0 & 1 & 0.8 \\
\hline & $>12$ years & 6 & 4.8 & 1 & 0.8 \\
\hline \multirow[t]{14}{*}{ Comorbidity } & DM & 0 & 0 & 10 & 8 \\
\hline & $\mathrm{HT}$ & 18 & 14.4 & 28 & 22.4 \\
\hline & Nephrolithiasis & 3 & 2.4 & 1 & 0.8 \\
\hline & Heart disease & 0 & 0 & 3 & 2.4 \\
\hline & Hepatitis C & 3 & 2.4 & 1 & 0.8 \\
\hline & Hepatitis B & 7 & 5.6 & 0 & 0 \\
\hline & Other diseases & 5 & 4 & 16 & 12.8 \\
\hline & DM, HT & 8 & 6.4 & 17 & 13.6 \\
\hline & HT, CVD & 13 & 10.4 & 5 & 4 \\
\hline & HT, Hepatitis C & 6 & 4.8 & 2 & 1.6 \\
\hline & HT, Hepatitis B & 9 & 7.2 & 0 & 0 \\
\hline & DM, HT, Hep B & 4 & 3.2 & 0 & 0 \\
\hline & DM, HT, CVD & 3 & 2.4 & 3 & 2.4 \\
\hline & Nothing & 46 & 36.8 & 39 & 31.2 \\
\hline
\end{tabular}

CAPD, continuous ambulatory peritoneal dialysis; DM, diabetes mellitus; HT, hypertension; CVD, cardiovascular disease. 
care, 89 people $(71.2 \%)$ were involved in activities to a good degree, and 83 people (66.4\%) had some form of pain/discomfort, and anxiety/depression. 102 people (81.6\%) undergoing CAPD had a good quality of life. These include those with the ability to walk/move to a good degree of people $(68.8 \%)$, individuals with adequate self-care $(85.6 \%)$, those that could perform activities to a good degree $(68 \%)$ and people with good feelings of anxiety/depression $77.6 \%$. Meanwhile, the pain/discomfort component was in moderate degrees of $51.2 \%$. For patients on CAPD, peritoneal dialysis which is home-based automated could increase the quality of life better than any other forms of dialysis. ${ }^{8}$

Table 3 shows that the QOL of hemodialysis patients and CAPD are the same, that is, they are in good degrees. Furthermore, the QOL of hemodialysis and CAPD patients were found to be $82.4 \%$ and $81.6 \%$ respectively. There is no significant difference between the five components of quality of life, namely the ability to walk/move, self-care, activities that can be done and anxiety / depression, all of which were in a good degree. However, the quality of life based on pain/discomfort for hemodialysis is mostly in good degrees about 66 people $(52.8 \%)$, while CAPD had a moderate degree with 64 people $(51.2 \%)$.

The difference is that hemodialysis patients without serious complications only feel pain twice a week during therapy. Furthermore, those that have been undergoing the treatment for a long time with adequate vascular access do not feel much pain at all and are more comfortable when they come to the hospital for hemodialysis. Meanwhile in CAPD, those that performed self-dialysis/fluid changes frequently at home (four times a day), were more likely to feel discomfort because they were bound by time. Pain is sometimes reported when they undergo the fluid replacement process. Self-care was the component with the highest QOL value in this study. However in CAPD, about $3.2 \%$ of the subjects were poor in caring for themselves, while those in hemodialysis we're not all in the good and moderate categories. It can then be concluded that in self-care, hemodialysis patients are more independent than CAPD. Self-care means that the patients take responsibility to care for themselves in each aspect of their mental, emotional, and spiritual needs. Patients with CAPD should be motivated and confident in self-care practices. Health professionals could also give certain educational programs to boost their self-efficacy to do self-care. . $^{-11}$

Quality of life based on activities that can be done by hemodialysis patients is slightly higher. Consequently, hemodialysis and CAPD patients that stated they were poor in their usual activities scored $1.6 \%$ and $8 \%$ respectively. This means that while carrying out daily activities, some of the respondents still need help from others even in small amounts. This component is considered significant enough for patients to achieve in improving their quality of life. On the psychological aspect, namely anxiety/sadness, most CAPD patients stated that there was no anxiety. Meanwhile, $2.4 \%$ of hemodialysis patients still felt sad and anxious. This can be because hemodialysis patients form strong social relationships and emotional bonds with each other and interact like siblings. Therefore, any death or decline will affect them psychologically even though death is a constant fear among CKD patients. Hemodialysis patients are prone to experience psychological issues and it may impact their quality of life. Emotional support is needed from friends and families so they can deal with the problems effectively. ${ }^{12-14}$

Both hemodialysis and CAPD patients undergo dialysis which is meant to improve their quality of life. Although these diseases come with their comorbidities, it does not pose a problem as the patients are able to adapt to situations and have the support of family members. Acceptance can improve the quality of life of

Table 2. Components of quality of life for hemodialysis and CAPD patients.

\begin{tabular}{|c|c|c|c|c|c|}
\hline Components of & Category & & & & \\
\hline quality of life & & n & $\%$ & n & $\%$ \\
\hline Ability to walk & Good & 89 & 71.2 & 86 & 68.8 \\
\hline & Moderate & 36 & 28.8 & 36 & 28.8 \\
\hline & Bad & 0 & 0 & 3 & 2.4 \\
\hline Self-care & Good & 116 & 92.8 & 107 & 85.6 \\
\hline & Moderate & 9 & 7.2 & 14 & 11.2 \\
\hline & Bad & 0 & 0 & 4 & 3.2 \\
\hline Usual activities & Good & 89 & 71.2 & 85 & 68 \\
\hline & Moderate & 34 & 27.2 & 30 & 24 \\
\hline & Bad & 2 & 1.6 & 10 & 8 \\
\hline Pain / discomfort & Good & 66 & 52.8 & 58 & 46.4 \\
\hline & Moderate & 58 & 46.4 & 64 & 51.2 \\
\hline & $\mathrm{Bad}$ & 1 & 0.8 & 3 & 2.4 \\
\hline Anxiety/sadness & Good & 83 & 66.4 & 97 & 77.6 \\
\hline & Moderate & 39 & 31.2 & 28 & 22.4 \\
\hline & Bad & 3 & 2.4 & 0 & 0 \\
\hline
\end{tabular}

CAPD, continuous ambulatory peritoneal dialysis.

Table 3. Comparison of quality of life for hemodialysis and CAPD patients.

\begin{tabular}{|c|c|c|c|c|}
\hline \multirow[t]{2}{*}{ Quality of life } & \multicolumn{2}{|c|}{ Hemodialysis } & \multicolumn{2}{|c|}{ CAPD } \\
\hline & n & $\%$ & n & $\%$ \\
\hline Good & 103 & 82.4 & 102 & 81.6 \\
\hline Moderate & 20 & 16 & 18 & 14.4 \\
\hline $\mathrm{Bad}$ & 2 & 1.6 & 5 & 4 \\
\hline
\end{tabular}

CAPD, continuous ambulatory peritoneal dialysis. 
Table 4. Results of Mann Whitney difference test analysis of quality of life for hemodialysis and CAPD patients.

\begin{tabular}{llccc} 
& Kidney substitution & n & Mean rank & p-value \\
Quality of life & Hemodialysis & 125 & 122.63 & 0.515 \\
& CAPD & 125 & 128.37 & \\
\hline
\end{tabular}

CAPD, continuous ambulatory peritoneal dialysis.

patients; thus health professionals could help patients to support their mental health and improve their coping strategies. In addition to this, accepting the disease means that the patients accept and let in all of the feelings with regards to the burden of diseases. Patients can put their faith to God and live at peace with the circumstances of their lives, no matter how difficult they are. ${ }^{15-17}$ These results provide a better understanding of psychological determinants of a CKD patient's quality of life. The results can further be investigated by nephrologists, which will lead to the development of specific psychological interventions, or other supporting public health services. ${ }^{6}$

Chen et al. examined the relationship between hemodialysis adequacy and the quality of life of 67 hemodialysis patients in Taipei. The result show that the group which achieved hemodialysis adequacy had a higher quality of life than the inadequate group. ${ }^{18}$ Furthermore, Rambod examined the relationship between the adequacy of hemodialysis patients in Iran and their quality of life; the result shows that there was a significant relationship between the two variables with a value of $\mathrm{p}=0.00 .{ }^{19}$ It can be concluded that adequate hemodialysis is one of the factors that play a role in improving the quality of life of patients, therefore it is an important indicator in the evaluation of hemodialysis. ${ }^{20}$

Previous study revealed that there is a correlation between quality of life, morbidity and mortality in end-stage renal disease patients. This study suggested that the assessment of quality of life should consider several psychosocial aspects such as depression, the burden of illness, and other supports from families and friends to increase the quality of life. ${ }^{21,22}$

Table 4 shows the results of statistical analysis using the Mann Whitney method, and the $p$ value $(0.515)>\alpha(0.05)$ which was obtained. This means that there is no difference between the QOL of patients undergoing hemodialysis and those with CAPD in the hospital. Respondents state that every time they perform hemodialysis, the target $\mathrm{Kt} / \mathrm{V}$ value is mostly achieved which helps improve their quality of life. Meanwhile, CAPD which is supposed to be more flexible and continuous during dialysis comes with co-morbidities and complications such as peritonitis, hernia and flow obstruction from CAPD access. Further, these conditions could affect the patients' quality of life. ${ }^{23-25}$

\section{Conclusions}

In conclusion, there was no difference in the quality of life between CKD patients undergoing hemodialysis and those having CAPD in the hospital. Furthermore, it is important for health workers to provide information about components of quality of life to patients and families with CKD who undergo hemodialysis and CAPD.
Correspondence: Ika Setyo Rini, School of Nursing, Faculty of Medicine, Universitas Brawijaya, Jl. Puncak Dieng, Kunci, Kalisongo, Kec. Dau, Malang, East Java Indonesia 65151.

Tel. +62.341569117 - Fax: +62.341564755

E-mail: ikasetyorini.14@gmail.com

Acknowledgment: The authors are grateful to the Faculty of Medicine, Universitas Brawijaya, Malang, Indonesia for their kind support and encouragements during this study.

Key words: Quality of life; chronic kidney disease; hemodialysis; continuous ambulatory peritoneal dialysis.

Contributions: All authors contributed equally to this research.

Conflict of interest: The authors declare no potential conflict of interest.

Ethics Approval: This study was approved by the Health Research Ethics Committee of the Faculty of Medicine, Universitas Brawijaya, Malang, Indonesia, with approval No. 400/199/K.3/302/2019.

Conference presentation: Part of this study was presented at the $1^{\text {st }}$ International Nursing and Health Sciences Symposium, November $13^{\text {th }}$ to $15^{\text {th }} 2020$, Brawijaya University, Malang, Indonesia.

Received for publication: 18 January 2021.

Accepted for publication: 22 March 2021.

${ }^{\circ}$ Copyright: the Author(s), 2021

Licensee PAGEPress, Italy

Journal of Public Health Research 2021;10:2209

doi:10.4081/jphr.2021.2209

This work is licensed under a Creative Commons Attribution NonCommercial 4.0 License (CC BY-NC 4.0).

\section{References}

1. Ene-Iordache B, Perico N, Bikbov B, et al. Chronic kidney disease and cardiovascular risk in six regions of the world (ISNKDDC): a cross-sectional study. Lancet Glob Health 2016;4:e307-19.

2. Atkins JL, Masoli JAH, Delgado J, et al. Preexisting comorbidities predicting COVID-19 and mortality in the UK Biobank community cohort. J Gerontol A Biol Sci Med Sci 2020;75:2224-30.

3. Ministry of Health Republic of Indonesia. Basic Health Research 2018. Jakarta: Ministry of Health Republic of Indonesia; 2018.

4. Shidler NR, Peterson RA, Kimmel PL. Quality of life and psychosocial relationships in patients with chronic renal insufficiency. Am J Kidney Dis 1998;32:557-66.

5. Lew SQ, Piraino B. Quality of life and psychological issues in peritoneal dialysis patients. Semin Dial 2005;18:119-23.

6. Poppe C, Crombez G, Hanoulle I, et al. Improving quality of life in patients with chronic kidney disease: influence of 
acceptance and personality. Nephrol Dial Transplant 2013;28:116-21.

7. Susanto Y, Alfian R, Rahim Z, et al. [Uji validitas dan reliabilitas kuesioner eq-5d bahasa indonesia untuk mengukur kualitas hidup pasien hemodialisa gagal ginjal kronik (Testing the validity and reliability of the Indonesian language eq-5d questionnaire to measure the quality of life of patients with chronic renal failure hemodialysis)].[Article in Indonesian]. J Ilm Manuntung 2018;4:41-7.

8. Wyld M, Morton RL, Hayen A, et al. A systematic review and meta-analysis of utility-based quality of life in chronic kidney disease treatments. PLoS Med 2012;9:e1001307.

9. Atashpeikar S, Jalilazar T, Heidarzadeh M. Self-care ability in hemodialysis patients. J Caring Sci 2012;1:31-5.

10. Ramezani T, Sharifirad G, Rajati F, et al. Effect of educational intervention on promoting self-care in hemodialysis patients: Applying the self-efficacy theory. J Educ Health Promot 2019;8:65.

11. Santana MBA, Silva DMGVda, Echevarría-Guanilo ME, et al. Self-care in individuals with chronic kidney disease on hemodialysis. Rev Gaucha Enferm 2020;41:e20190220.

12. Davaridolatabadi E, Abdeyazdan G. The relation between perceived social support and anxiety in patients under hemodialysis. Electr Phys 2016;8:2144-9.

13. Pretto CR, Winkelmann ER, Hildebrandt LM, et al. Quality of life of chronic kidney patients on hemodialysis and related factors. Rev Latino-Am Enfermagem 2020;28:e3327.

14. Finnegan-John J, Thomas VJ. The psychosocial experience of patients with end-stage renal disease and its impact on quality of life: Findings from a needs assessment to shape a service. ISRN Nephrol 2013;2013:1-8.

15. Pompey CS, Ridwan MN, Zahra AN, et al. Illness acceptance and quality of life among end state renal disease patients undergoing hemodialysis. Enferm Clin 2019;29:s128-33.

16. Siregar CT, Rhamayani M. Self-acceptance of chronic caused failure patients that have a hemodialysis in Medan. Indonesian
J Nurs Sci 2019;1:18-24.

17. Chiang HH, Livneh H, Guo HR, et al. Effects of acceptance of disability on death or dialysis in chronic kidney disease patients: a 3-year prospective cohort study. BMC Nephrol 2015;16:202.

18. Chen Y-C, Hung K-Y, Kao T-W, et al. Relationship between dialysis adequacy and quality of life in long-term peritoneal dialysis patients. Perit Dial Int 2000;20:534-40.

19. Rambod M, Rafii F. Perceived social support and quality of life in Iranian hemodialysis patients. J Nurs Scholarsh 2010;42:242-9.

20. Septiwi C, Yetti K, Gayatri D. [Hubungan Adekuasi Hemodialisis Dengan Kualitas Hidup Pasien Di Unit Hemodialisis RS Prof. dr. Margono Soekarjo Purwokerto Jawa Tengah (The relationship between hemodialysis adequacy and quality of life for patients in the Hemodialysis Unit of Margono Soekarjo, Purwokerto, Central Java)].[Article in Indonesian]. Maj Keperawatan Unpad 2011;13:1.

21. Cruz MC, Andrade C, Urrutia M, et al. Quality of life in patients with chronic kidney disease. Clinics 2011;66:991-5.

22. Kimmel PL, Patel SS. Quality of life in patients with chronic kidney disease: focus on end-stage renal disease treated with hemodialysis. Semin Nephrol 2006;26:68-79.

23. Tian Y, Xie X, Xiang S, et al. Risk factors and outcomes of high peritonitis rate in continuous ambulatory peritoneal dialysis patients: A retrospective study. Medicine (Baltimore) 2016;95:e5569.

24. Hsieh YP, Chang CC, Wen YK, et al. Predictors of peritonitis and the impact of peritonitis on clinical outcomes of continuous ambulatory peritoneal dialysis patients in Taiwan--10 years' experience in a single center. Perit Dial Int 2014;34:8594.

25. Kerschbaum J, König P, Rudnicki M. Risk factors associated with peritoneal-dialysis-related peritonitis. Int $\mathrm{J}$ Nephrol 2012;2012:1-11. 